\title{
Children's Interpretations of Indefinite Object Noun Phrases
}

\author{
Evidence from the Scope of Negation
}

Irene Krämer

\section{Introduction}

In a number of languages, direct object Noun Phrases may optionally move out of the VP, across elements like adverbs or operators, to a higher position, a phenomenon which has become known as scrambling. (cf. Mahajan (1990), De Hoop (1992), Diesing (1992)). Subtle differences between the interpretations of the scrambled and unscrambled NPs have been observed.

This paper reports an experiment investigating the interpretation of scrambled and unscrambled indefinite object NPs by Dutch children. Below I will present some facts about scrambling that a child learning Dutch must acquire.

The scrambled indefinite object NP (to the left of the adverb) in (1a) is often characterized as "specific" or "presupposed" (c.f. Diesing (1992)): een baby seems to refer to a particular baby. In contrast, the interpretation of the unscrambled NP (to the right of the adverb) in (1b) is "non-specific": no particular baby is intended.

(1) a. De jongen heeft een baby zachtjes gekieteld.

the boy has a baby softly tickled

'The boy softly tickled a baby.'

b. De jongen heeft zachtjes een baby gekieteld.

the boy has softly a baby tickled

'The boy softly tickled a baby.'

The facts are a little more complicated when a VP operator rather than a modifying adverb marks the border of the VP, as in example (2). (In (2b), the negation is visible only on the indefinite article of the object NP. However, I will assume that the object NP is in VP internal position). The specific/non-specific contrast between scrambled and unscrambled NPs is the same as in (1a-b), but in addition, there is a scope difference: the indefinite NP in (2a) is outside the scope of the negative operator that it has scrambled over: we can be assured of the 
existence of a referent for een marsmannetje. The unscrambled object in $(2 \mathrm{~b})$, on the other hand, is in the scope of the negative operator, as is shown by the fact that we cannot infer from $(2 b)$ that any Martians exist.

(2) a. De jongen heeft een marsmannetje niet gezien.

the boy has a martian not seen

'The boy did not see a Martian.'

b. De jongen heeft geen marsmannetje gezien.

the boy has no martian seen

'The boy did not see a Martian.'

Examples (1) and (2) show that the interpretation of indefinite object NPs may be affected by at least two factors: First, by position: is the NP inside or outside the VP? Second, by the scope of operators: is the NP inside or outside the scope of VP operators like negation? The task that the Dutch child faces is to acquire the way in which these factors combine.

In Section 2, I will present Van Geenhoven's 1996 analysis of indefinite Noun Phrases, which captures the different interpretations of the indefinite object NPs in the examples above, and isolates a principle that underlies scrambling of indefinite object NPs.

In Section 3, I will present a hypothesis for the acquisition of indefinite NP interpretations. Sections 4 and 5 present an experiment that tests this hypothesis for Dutch children from 4 to 7 years old, the results, and a discussion of their implications.

\section{A semantic account of scrambling}

The analysis of scrambling that I will adopt in the remainder of this paper is Van Geenhoven's 1996 theory of indefinites. For a detailed discussion of the differences between this and several other approaches (Diesing (1992), De Hoop (1992)) I refer to Van Geenhoven (1996). This analysis was chosen, because it provides a very explicit account of the different NP interpretations that are associated with the scrambled and unscrambled positions. Two kinds of indefinite NPs are distinguished: predicative NPs, and free variable NPs. Predicative NPs are interpreted by a mechanism of Semantic Incorporation, whereas free variable NPs are interpreted by a mechanism of Accommodation. These different interpretive mechanisms underlie the differences between the $(-a)$ and $(-b)$ sentences in examples (1) and (2). Across languages, different means may be used to indicate whether an object NP is a predicate or a free variable, such as overt noun incorporation, case marking, or syntactic position. Dutch avails itself of the last 
option. Below I will briefly sketch how each of the mechanisms for NP interpretation works, and how they can explain examples (1) and (2) above.

\section{Semantic Incorporation}

Van Geenhoven argues that indefinites may introduce a predicate in the sense of Carlson (1977) into the discourse, rather than a variable as in Heim (1982). By Semantic Incorporation, the verb absorbs the nominal predicate as a restriction on a variable that is introduced by this verb. This predicative NP receives its existential interpretation through the verb.

In concrete terms, if we assume that tickling takes place in (1b), De jongen heeft zachtjes een baby gekieteld (The boy has softly tickled a baby), we must assume that there is an entity that is being tickled. In this way, the verb introduces a variable for the direct object. The predicative NP een baby restricts the direct object variable to one exemplar of the class of babies.

Semantic Incorporation explains why the direct object NP in (2b) is in the scope of the negative operator: since a negation is operating on the verb, we cannot assume that seeing takes place. As a result, there is no variable that is introduced by the verb, and we cannot infer from (2b) that any Martians exist.

\section{Accommodation}

Free variable indefinites in addition to their predicative content carry a variable which must be bound. It is bound by discourse through the mechanism of Accommodation, in the sense of Van der Sandt (1992). Van Geenhoven proposes that Accommodation does not only play a role in anaphora and presupposition resolution, but also in the binding of free variable indefinites. Accommodation is an interpretive mechanism which shifts the descriptive content of an expression to that position in a logical representation in which it has to be interpreted. In the case of free variable indefinites, this means that some information that already is part of the discourse at the moment at which the free variable indefinite enters it, binds the indefinite's variable. Such an older part of the discourse content will then justify the occurrence of the free variable indefinite. Thus, the free variable indefinite is interpreted by establishing a link between the NP and an earlier piece of information.

The part of content that binds the indefinite's variable may consist of information that is mentioned in the same sentence as the free variable indefinite, or in the preceding utterance, or even information that is in a broader sense part of the discourse context.

However, Accommodation must observe certain restrictions, one of which is Bridging, a psychological mechanism (Clark (1977)). Bridging restricts accommodation of the NP to levels at which the existence of a referent of the NP is 
plausible. Imagine a situation in which the discourse participants have just left a day care center, and one of them utters the following sentence:

$\mathrm{Al}$ die moeders hebben een baby zachtjes gekieteld. all those mothers have a baby softly tickled 'All those mothers softly tickled a baby.'

In (3), the object NP een baby can be accommodated to 'all those mothers', i.e., for each of those mothers there is a baby that they tickled. However, the NP may also be accommodated at the level of discourse context, which causes een baby to be interpreted as 'one of the babies in the day care center'. Accommodation at either of these levels observes Bridging. Accommodation that does not observe Bridging cannot take place: een baby cannot be interpreted as 'a baby who was not at the day care center' since there is nothing in the discourse that renders such an interpretation plausible.

In this way, Accommodation restricted by Bridging accounts for the "specific" or "presupposed" interpretation of the scrambled NPs in (1a) and (2a): When the indefinite enters the discourse, the discourse already contains information that renders the existence of the referent of the new NP plausible.

\section{Acquisition}

Following the analysis outlined in Section 2, we may state that interpreting a predicative indefinite only requires knowledge of the N-restriction, say, "baby" or "cookie", and the ability to apply this as a restriction on some variable. Children show that they recognise the predicative core as soon as they can apply a word like "baby" or "cookie" to separate referents that match the restriction. Furthermore, children show that they can use the predicates as restrictions on a variable, even in the absenc of a particular referent, when they say things like: "want cookie". We can therefore be assured that the use of NPs as predicates is acquired by age 3 .

In contrast to predicative indefinites, free variable indefinites must be interpreted in terms of preceding discourse. This means that a link has to be established between a present utterance, and previous ones. Studies in child production by Karmiloff-Smith $(1979,1981)$ and Hickmann (1982) show that children through at least age 6 use hardly any linguistic means to construct a cohesive discourse. There is no evidence that children's use of pronominal and definite NPs is intralinguistic or anaphoric. Rather, both authors' analysis is that children's definite NPs and pronouns only refer, or apply to, the physical context. In addition, from studies in the comprehension of pronouns, we know that children 
may interpret sentences like : John tickled him, as if John were tickling himself. This error is still found at age 8 (Koster (1993). Whatever may be the exact cause of this child error, clearly the anaphoric link that the child needs to make in order to interpret the pronoun is not established in a proper way. Considering both the production and comprehension studies, it is clear that interpreting NPs in terms of preceding discourse, whether full NPs or pronouns, may indeed be problematic for children through at least age 6.

Extending the findings discussed above to the acquisition of indefinite NP interpretation, we arrive at the hypothesis that children will disprefer interpreting indefinite NPs in terms of preceding discourse. This means that children will initially try to avoid having the indefinites bound by the discourse through Accommodation, and instead interpret them independently of the preceding discourse. This hypothesis is stated in (4):

Acquisition of NPs proceeds from non-discourse bound to discourse bound NP interpretations

The prediction is that children will fail to accommodate at least part of the scrambled indefinite NPs. This leaves them the option to interpret the indefinites as predicates, because the verb can provide a variable to predicate over. On the assumption that children's preference for non-discourse bound interpretations is sufficiently strong to make them ignore the clue to the adult-like interpretation that the scrambled NP's position provides, this means that the children will interpret scrambled NPs as if they were unscrambled.

Note that this hypothesis does not predict the same course or age of development for definite NPs as for indefinites. As soon as children have discovered that the definite article either indicates that the NP is known information (Heim 1982) or unique (Russell 1905), they are forced to take the discourse into account if they want to interpret the article.

\section{Experiment: scrambling across negation}

\subsection{Method and design}

An experiment was set up to test the prediction in Section 3, which exploits the truth-conditional difference that results from scrambling, or not scrambling, an indefinite NP across negation. Example (5) contains a pair of test sentences that was used in the experiment. 
(5) a. De jongen heeft een vis niet gevangen.

the boy has a fish not caught

'The boy did not catch a fish.'

b. De jongen heeft geen vis gevangen.

the boy has no fish caught

'The boy did not catch a fish.'

The scrambled indefinite NP een vis in (5a) has an expected adult interpretation as a free variable, which must accommodate. Thus, for (5a) to be true, there must be a fish that is not caught by the boy. The unscrambled indefinite NP geen vis in $(5 \mathrm{~b})$ has an expected adult-like interpretation as a predicate over a variable that is introduced by the verb. This entails that the NP is affected by the negative operator, such that for $(5 \mathrm{~b})$ to be true, there must not be any fish that are caught by the boy.

In a modified truth value judgment task, subjects judged whether test sentences like $(5 \mathrm{a}, \mathrm{b})$ matched picture stories. There were two test-conditions, "scrambled" and "unscrambled". In the scrambled condition, the test sentences matched the situation in the story, in the unscrambled condition, the sentences were a mismatch to the situation in the story.

A good match for the picture stories to the sentences in the scrambled condition requires a discourse that allows for accommodation of the object NP. This requirement is met by providing a group of object referents, e.g. fish, one of which is the unaffected referent. Thus, a partitive reading of the scrambled NP is easily available.

Below is an example of a test item. 
(6)

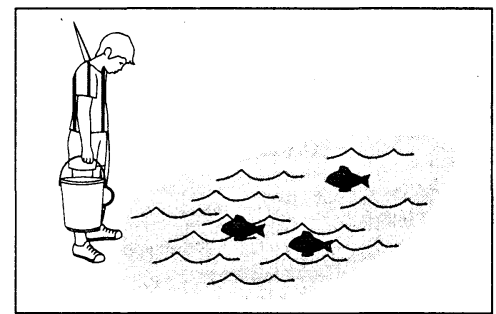

Dit is een jongen, en dit zijn vissen.

Die wil hij denk ik vangen

'This is a boy, and these are fish.

I think he wants to catch them'

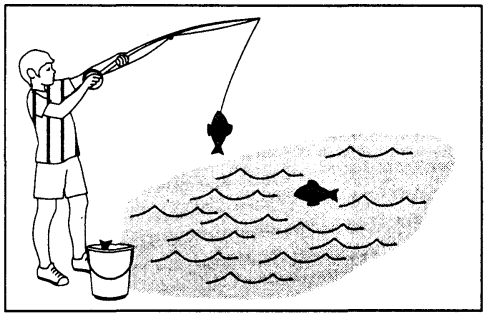

En hier vangt hij een vis

'And here he's catching a fish'

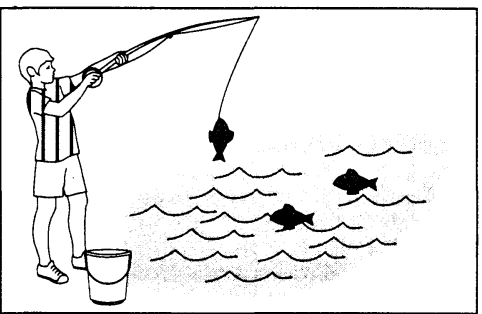

Hier vangt hij een vis 'Here he's catching a fish'

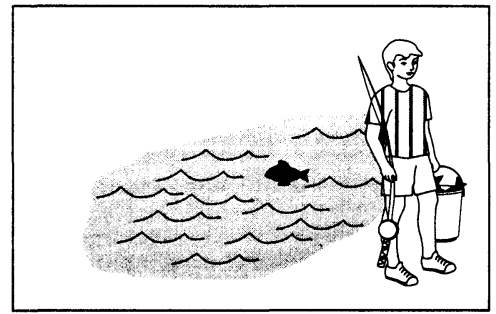

En nu gaat hij weer weg.

'And now, he's leaving'

Puppet: "Hee, ik zie wel wat er gebeurd is:

De jongen heeft geen vis gevangen (incorrect)/

De jongen heeft een vis niet gevangen (correct). Heb ik dat goed geraden?"

Puppet: 'Hey, I see what happened:

The boy has no fish caught (incorrect)/

The boy has a fish not caught (correct). Did I guess right?'

The other test items contained: picking apples, stealing necklaces, breaking vases, ironing blouses and taking cookies. All actions denoted by the verbs resulted in an easily visible change of state or location of the object.

A between-subjects design was chosen because the difference between the contrasting sentences is rather subtle - a within-subjects design might cause confusion with the subjects, or carry-over effects. One group of subjects received test sentences with scrambled indefinite objects, the other group received test sentences with unscrambled objects. Both groups received the same picture stories. 


\subsection{Procedure}

The experimenter tells the subject short stories that accompany the pictures. In a guessing game, a puppet asks the child whether the test sentence matches the story. Whenever the subject rejects the sentence, the puppet invites her to explain why. For adults, the puppet routine was omitted.

There were six test items, mixed with six filler items. The filler items served both as controls and as distractors. They consisted of stories similar to the test items, the test sentences containing an indefinite object that was scrambled across negation in the scrambled condition, and remained in unscrambled position in the unscrambled condition. For three filler items, the correct response was to reject the test sentence, both on a predicative and a free variable interpretation of the object NP. For the remaining three filler items, the correct response was to accept the test sentence. For example, one filler item shows a woman putting a dirty plate on the counter top, and leaving it there. The test sentence De vrouw heeft een bord niet afgewassen (The woman did not clean a plate) is correct, whether een bord (a plate) is interpreted inside, or out of the scope of negation. As control items, the filler items enabled checking whether the children kept paying attention to the test sentences and stories, and whether they did not adopt a strategy of responding either always yes, or no. As distractors, the filler items offered a break from the story-pattern of the test items. The test items always contained three potential object referents, two of which were acted upon, while one remained untouched. In contrast, the filler stories featured either one, two, or three potential object referents, which all were either acted upon, or not acted upon.

The test and filler items were preceded by four warm-up items. Test items and filler items were presented in a random order, which was fixed across subjects.

All sentences were pronounced with the intonation that matched most naturally the expected adult interpretation of the sentence. In the scrambled condition, scrambled indefinites were always destressed. In the unscrambled condition, the sentences were always spoken with normal focal stress on the VP, including the negation.

\subsection{Subjects}

Fifty children and ten adults, all native speakers of Dutch, took part in the experiment. The children were drawn from three primary schools, the adult subjects were university students (non-linguists). Twelve children were excluded from the analysis, because they failed two or more controls (filler items). For the 
remainder of this paper, "subjects" will only refer to the experimental subjects that were included in the analysis.

The child subjects, who ranged in age from $4 ; 2.11$ to $7 ; 6.12$, were divided into three age groups, more or less according to the cut-off points that are used in the school system. All the subjects from the two youngest age groups were preschoolers, the children in the oldest age group were in school group 3 (first grade) and had received nearly a year of reading education.

Age group I, ages between 4;0 and 5;6, consisted of seven subjects in the scrambled condition and six in the unscrambled condition (mean age in each condition $4 ; 11$ ).

Age group II, ages between 5;6 and 6;10, consisted of eight subjects in the scrambled condition, six in the unscrambled condition (mean age in each condition 6;0). Age group III, ages between 6;10 and 7;10, (mean age 7;1), was added later on; this group consisted of eleven subjects, all of them in the scrambled condition.

\section{$4.4 \quad$ Results}

The percentages of yes- and no-responses in either condition are shown in Table 1.

Table 1. Percentage of acceptance or rejection of the test sentences in the scrambled and unscrambled conditions

\begin{tabular}{|l|l|l|l|l|}
\hline responses & \multicolumn{2}{|l|}{ unscrambled condition } & \multicolumn{2}{l|}{ scrambled condition } \\
\hline age groups & acceptance & rejection & acceptance & rejection \\
\hline I $4-5 ; 6$ & $0 \%$ & $100 \%(36)$ & $17 \%(7)$ & $83 \%(35)$ \\
\hline II $5 ; 6-6 ; 10$ & $0 \%$ & $100 \%(36)$ & $23 \%(11)$ & $77 \%(37)$ \\
\hline III $6 ; 10-7 ; 10$ & -- & -- & $10 \%(7)$ & $89 \%(59)$ \\
\hline total for children & $0 \%$ & $100 \%(72)$ & $16 \%(25)$ & $84 \%(131)$ \\
\hline adults & $0 \%$ & $100 \%(24)$ & $100 \%(36)$ & $0 \%$ \\
\hline
\end{tabular}

In the unscrambled condition, both children and adults reject the test sentence $D e$ jongen heeft geen vis gevangen as a description of the situation presented by the picture story in (6). In the scrambled condition, the children reject the test sentence De jongen heeft een vis niet gevangen in $84 \%$ of the cases, whereas the adults always accept it as a match to the situation presented in (6). Thus, in the unscrambled condition, $100 \%$ of the child responses are adult-like, whereas in the scrambled condition, only $16 \%$ of the child responses are adult-like. 
The percentage of adult-like responses varies between $10 \%$ and $23 \%$ per age group, while the oldest age group even has the lowest percentage of adult-like responses. Most children never gave an adult-like response: all of the adult-like responses occurred with only six children, two in each age group.

Nearly each rejection of a test sentence was motivated by the children, either by verbally explaining that, for instance, the boy DID catch fish, or by pointing at one or both of the fish that were caught. This is a motivation that makes sense for the adult interpretation of the sentences in the unscrambled condition, since with an unscrambled object, the sentence means 'The boy did not catch any fish'. Strikingly, the children motivated their rejection of the test sentences in the same way in both conditions.

Subsequently, the subjects were classified according to response pattern: If all or all-but-one of a subject's responses were "yes", i.e. accepting the test sentence, the subject was classified as having an acceptance-pattern. If all, or all-but-one of a subject's responses were "no", i.e. rejecting the test sentence, the subject was classified as having a rejection-pattern. There was no need for including a third category; since the subjects were remarkably consistent in their responses. The way in which subjects with an acceptance-pattern and a rejection-pattern divide across the conditions can be read off Table 2 .

Table 2. Response patterns in the scrambled and unscrambled conditions

\begin{tabular}{|l|l|l|l|l|}
\hline response patterns & \multicolumn{2}{|l|}{ unscrambled condition } & \multicolumn{2}{l|}{ scrambled condition } \\
\hline age groups & acceptance & rejection & acceptance & rejection \\
\hline I $4-5 ; 6$ & 0 & 6 & 1 & 6 \\
\hline II $5 ; 6-6 ; 10$ & 0 & 6 & 2 & 6 \\
\hline III $6 ; 10-7 ; 10$ & -- & -- & 1 & 10 \\
\hline total children & 0 & 12 & $4(15 \%)$ & $22(85 \%)$ \\
\hline adults & 0 & 4 & 6 & 0 \\
\hline
\end{tabular}

Table 2 shows that all of the children in the unsorambled condition, but only four out of twenty-six children in the scrambled condition (15\%) have an adult-like response pattern. Again, there is no difference between the age groups. 


\section{Summary and discussion}

The results of the experiment show that for children between $4 ; 0$ and $7 ; 10$, there is hardly a distinction between scrambled and unscrambled indefinite NPs. Adults will only have a predicative interpretation of an NP if it is in unscrambled position. In contrast, $85 \%$ of the children who judged a sentence with an indefinite NP that was scrambled across negation interpreted the NP in the scope of the negation, indicating that they interpreted the NP as a predicate. This is confirmed by the fact that children motivate their judgments of sentences with scrambled indefinites in the same way as their judgments of sentences with unscrambled indefinites.

These results support the hypothesis in (4): most children under 7;10 prefer a non-discourse bound interpretation of scrambled indefinite object NPs, disregarding their position. Children of the same age uniformly interpret unscrambled indefinite objects as predicates, i.e. also as non-discourse bound, in an adult-like fashion. One might argue that the children's misinterpretations could be due to problems with negation, rather than NP interpretation. However, an experiment that made use of the operator twice to investigate children's indefinite NP interpretations yielded similar results (Krämer 1998).

I would argue that the late age of acquisition of the interpretation of scrambled indefinites supports the view that scrambling should be regarded as an interface phenomenon, rather than a part of the core grammar (cf. Reinhart 1995). Taking such a view offers an opportunity to investigate the interaction of the development of syntax, discourse semantics and discourse skills during the process of language acquisition.

\section{Acknowledgments}

Thanks to Peter Coopmans, Ken Drozd and a reviewer for comments on this paper.

\section{References}

Clark, H. (1977) 'Bridging'. In P. N. Johnson-Laird and P. C. Wason, eds., Thinking, 411-420. Cambridge University Press, Cambridge.

Diesing, M. (1992) Indefinites, MIT Press, Cambridge, MA.

Geenhoven, V. van (1996) Semantic Incorporation and Indefinite Descriptions: Semantic and Syntactic Aspects of Noun Incorporation in West Greenlandic. Ph.D. Dissertation, EberhardKarls University, Tübingen. 
Heim, I. R. (1982) The Semantics of Definite and Indefinite Noun Phrases. Ph.D. Dissertation, University of Massachussetts at Amherst.

Hickmann, M. (1982) The Development of Narrative Skills: Pragmatic and Metapragmatic Aspects of Discourse Cohesion. Ph.D. dissertation, University of Chicago.

Hoop, H. de (1992) Case Configuration and Noun Phrase Interpretation. Ph.D. Dissertation, Groningen University.

Karmiloff-Smith, A. (1979) A Functional Approach to Child Language, a Study of Determiners and Reference. Cambridge University Press, Cambridge.

Karmiloff-Smith, A. (1981) 'The Grammatical Marking of Thematic Structure in the Development of Language Production'. In W. Deutsch, ed., The Child's Construction of Language, 123- 147. Academic Press, London.

Koster, Ch. (1993) Errors in Anaphora Acquisition. Ph.D. Dissertation, Rijksuniversiteit Utrecht.

Krämer (1998) Children's Interpretation of Scrambled Indefinites: Late Acquisition. Ms, Max Planck Insitute for Psycholinguistics.

Mahajan, A. (1990)The A/A-bar Distinction and Movement Theory. Ph.D. Dissertation, MIT.

Reinhart, T. (1995) Interface Strategies. OTS Manuscript, Utrecht University.

Sandt, R. van der (1992) 'Presupposition Projection and Anaphora Resolution'. Journal of Semantics 9, 333-377.

Schaeffer, J. (1997) Direct Object Scrambling in Dutch and Italian Child Language. Ph.D. Dissertation, UCLA. 